\title{
CHRONIC PYELONEPHRITIS AND ARTERIAL HYPERTENSION
}

\author{
By ALLAN M. BUTLER \\ (From the Department of Pediatrics of the Harvard Medical School and the Infants' and \\ Children's Hospitals, Boston)
}

(Received for publication July 7, 1937)

The present paper presents certain clinical and pathological evidence which demonstrates that hypertension not infrequently is associated with pyelonephritis before there is any appreciable diminution in renal function and that hypertension which is secondary to unilateral pyelonephritis may disappear when the involved kidney is removed.

Ritter and Baehr (1) described renal arteriolar sclerosis in congenital polycystic disease of the kidney and remarked upon a preliminary period of arterial hypertension, cardiac hypertrophy and hyposthenuria that usually precedes the terminal uremia in that disease. Bell and Pedersen (2) stated that " hypertension has never been reported in pyelonephritis." Volhard (3) and Schwarz (4) reported hypertension in patients with contracted kidneys (schrumpfnieren). Longcope and Winkenwerder (5) reported elevated blood pressures in the uremic phase of cases of chronic pyelonephritis. Weiss, Parker and Robb (6) observed that patients with malignant hypertension frequently had a history of chronic pyelonephritis, pyelitis, or perinephritic abscess. They suggested that such a renal infection may heal but that the hypertension initiated by it may continue to progress. Fishberg (7) mentioned the hypertension that may occur in children in the presence of urinary obstruction and in polycystic disease of the kidney when there is extensive destruction of renal parenchyma. He stated, however, that hypertension does not occur in that disease if there are extensive areas of intact parenchyma. Peters (8), Peters, Lavietes and Zimmerman (9), and Zimmerman and Peters (10) have called attention to the frequency with which pyuria and eclampsia are associated in pregnancy and suggested a relation between urinary tract infection and hypertension. Kimmelstiel and Wilson (11) studied thirteen patients with acute diffuse pyelonephritis; nine died in uremia, and hypertension was present in four of these. Two patients presented what was interpreted as essential hypertension with superimposed diffuse acute pyelonephritis but without renal insufficiency. Twenty-six patients who suffered from diffuse chronic pyelonephritis were also studied; of these, hypertenision and uremia were associated in sixteen; hypertension alone was present in four, and uremia without hypertension in six. Hypertension without marked renal insufficiency, therefore, was present in six of their patients. In the majority of in. stances, they were unable to decide whether they were dealing with a primary "vascular" hypertension or with a secondary " renal" hypertension.

In spite of the frequency with which pyelonephritis is encountered in childhood (12), we have found no report of a serious hypertension occurring in the pyelonephritis of childhood before renal insufficiency was present. Interestingly enough, Amberg (13) in reporting twenty-five cases of hypertension in children included five patients with pyuria or bacilluria but made no particular comment upon the presence of pyelonephritis in these patients.

The records concerning the blood pressures of many of the patients admitted to this hospital with chronic pyelonephritis are not complete enough to supply accurate information concerning the respective times at which the hypertension, if present, and renal insufficiency first appeared, but such data as are available seem significant. During the past ten years fifteen children between three and eleven years of age were shown at necropsy to have pyelonephritis. Adequate records of the blood pressures of seven of these patients are not available. The records of the blood pressures for the remaining eight patients show systolic pressures ranging from 250 to $140 \mathrm{~mm}$. $\mathrm{Hg}$ and diastolic pressures from 170 to $110 \mathrm{~mm}$. $\mathrm{Hg}$, the average systolic and diastolic pressures being respectively, 190 and $140 \mathrm{~mm}$. Hg. Two of these patients (Cases 3 and 4 reported below) had hypertensive crises and died of cardiac failure before 
significant nitrogen retention occurred. The clinical histories of two others of the group studied pathologically indicated that the pyelonephritis and hypertension preceded severe nitrogen retention. During the same ten year period three patients with pyelonephritis and hypertension died and permission for autopsy was not obtained. The histories of two of these patients (Cases 1 and 2 below) indicate that the pyelonephritis and hypertension preceded significant renal insufficiency and nitrogen retention. During this same definite proof that the pyelonephritis preceded the hypertension.

The fifth case reported here is that of a patient who, coincident with a ureteral calculus, was found to have a unilateral pyelonephritis and during the course of the next 8 months developed hypertension and cardiac failure. The removal of the one infected kidney was followed by clearing of the urine and a return of the blood pressure to normal where it has remained for 20 months. In this case there is strong evidence that the pye-

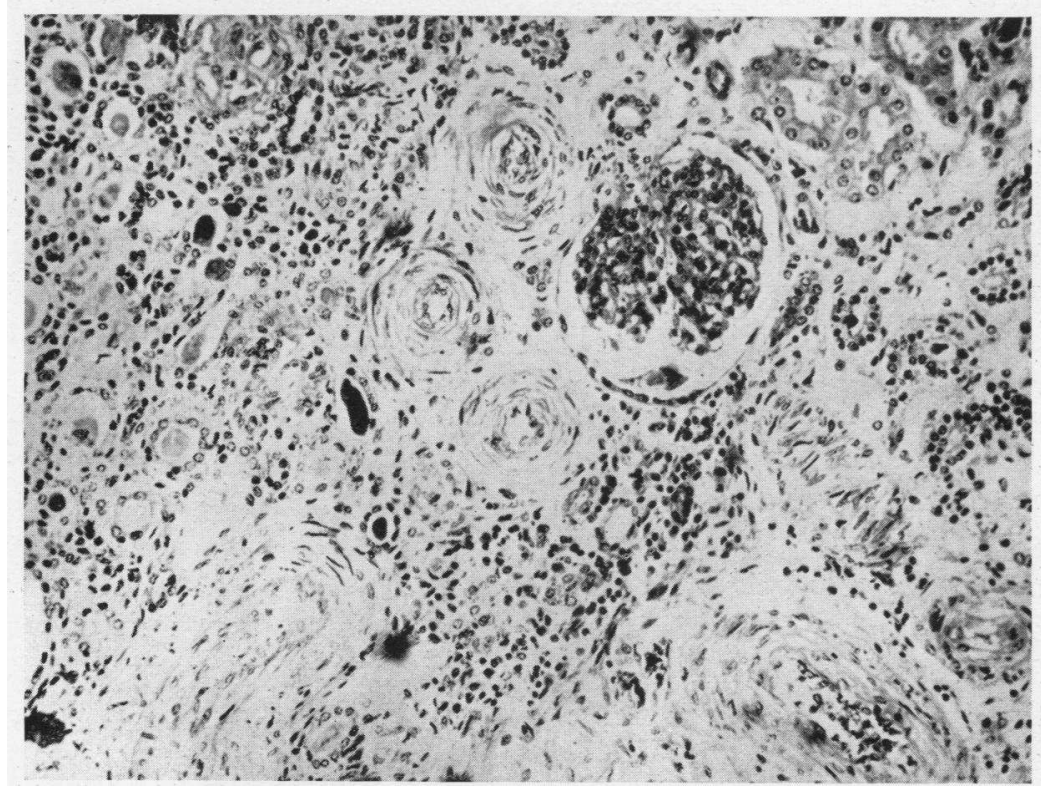

Fig. 1. Photomicrograph of Microscopic Section Prepared from Kidney of CASE 4

Hematoxylin and eosin. Reduced from a magnification of 240 diameters. Note prominence and thickening of walls of small arterioles, interstitial infiltration and casts in the renal tubules. Both chronic pyelonephritis and nephrosclerosis were present in the various sections examined.

period nine patients with pyelonephritis and hypertension were admitted to the hospital and when last seen were living. Of these patients only one had renal insufficiency, and in this one the pyelonephritis and hypertension preceded the appearance of the diminished renal function.

Thus we have fifteen patients (six dead and nine living) who have had chronic pyelonephritis and hypertension over a period of years before there was appreciable diminution in kidney function. The detailed records of four of these patients are given below. In these cases there is no lonephritis preceded the hypertension and in some way had a causal relation to it.

Subsequently, another patient, Case 6, who had a unilateral pyelonephritis and hypertension which was relieved by right nephrectomy, and whose history suggested a relation between the renal lesion and hypertension, was seen on the pediatric ward of the Massachusetts General Hospital through the kindness of Dr. Harold Higgins and Dr. J. D. Barney. ${ }^{1}$

${ }^{1}$ A full report of this patient will be made by $\mathrm{Dr}$. Barney. It is through his kindness that a brief description is given with the cases reported here. 


\section{DISCUSSION}

It is of particular interest in relation to the last two patients that Moritz (14) reported three patients with essential hypertension in each of whom the renal arteriolar sclerosis was found at necropsy to be limited to one kidney.

Both chronic pyelonephritis and nephrosclerosis were revealed by postmortem examinations performed on two of our patients (Cases 3 and 4). The photomicrograph shown in Figure 1 illustrates the extensive character of the renal arteriolar sclerosis in Case 4. From the clinical ex- tients who suffered from both pyelonephritis and hypertension.

A detailed review of the clinical observations concerning the association of pyelonephritis and hypertension in patients studied in this hospital, however, led to the hypothesis that the hypertension might well be related to the local effect of the pyelonephritis rather than to the renal insufficiency encountered late in the disease. When this hypothesis was put to an empirical test by the removal of the infected kidney in a patient who suffered from unilateral pyelonephritis and hyper-

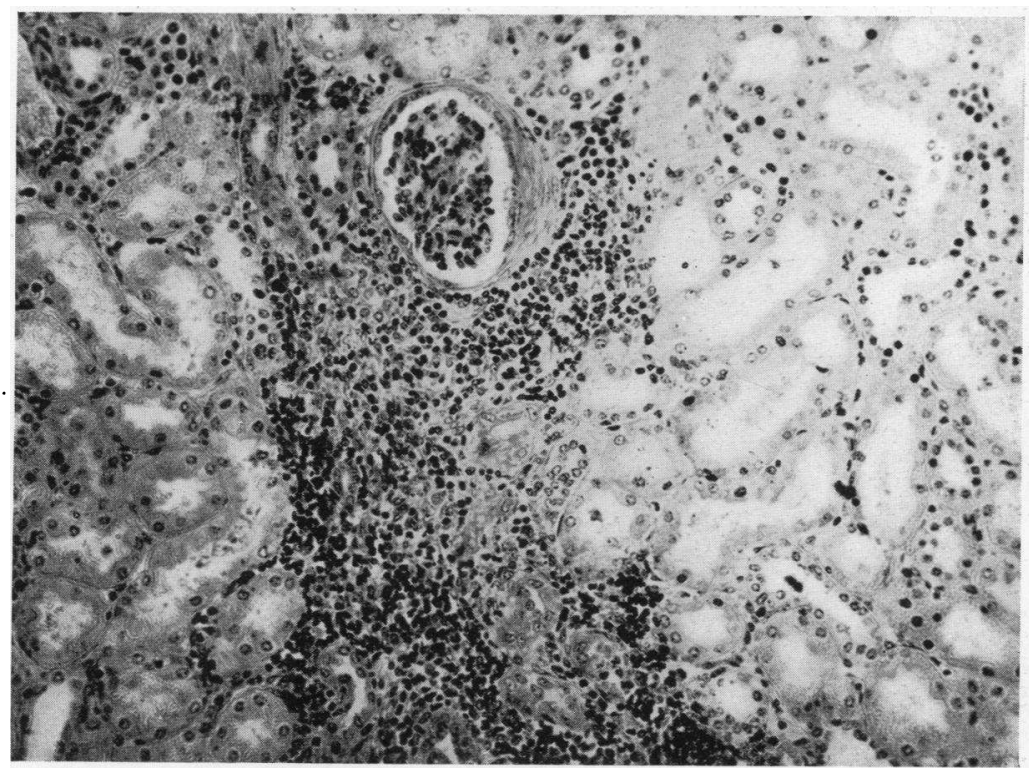

Fig. 2. Photomicrograph of Microscopic Section Prepared from the Kidney Removed From Case 5

Hematoxylin and eosin. Reduced from a magnification of 240 diameters. Note diffuse pyelonephritis. No thickening of arterioles comparable to that noted in Case 4 is demonstrable.

amination of the retinal and peripheral vessels it is proable that nephrosclerosis was present in addition to the pyelonephritis in Cases 1 and 2 . It is clear that no conclusion may be drawn from our evidence in these four cases concerning the relative time of onset of the pyelonephritis and the nephrosclerosis or their relative importance in the production of hypertension. The same difficulty was encountered by Kimmelstiel and Wilson (11) when they attempted to decide whether they were dealing with primary "vascular" hypertension or with secondary " renal" hypertension in their pa- tension (Case 5) it was found to be effective. The results in Dr. Barney's case (Case 6) lend further support to such a relation between the pyelonephritis and hypertension.

Pathological examination of the kidney removed from our patient, Case 5, showed in addition to severe pyelonephritis very early sclerosis of the renal arterioles. These vascular lesions were not sufficiently advanced or prominent to merit the term of nephrosclerosis as it is ordinarily understood. The photomicropraph of Figure 2 illustrates the absence in Case 5 of such a 
renal arteriolar sclerosis as observed in Case 4. It is well known that chronic inflammatory processes of various kinds are accompanied by vascular changes in the involved areas. In considering the rôle of ischemia and infections in the production of hypertension, it is of interest that Parker and Weiss (15) observed arteriolar sclerosis in the lung in the presence of pulmonary congestion and infection. That obstruction to the flow of urine from one kidney may result in a rise in blood pressure has been shown by Bell and Pedersen (2). Goldblatt, Lynch, Hanzal, and Summerville (16), and Wood and Cash (17) have produced hypertension in dogs by partially obstructing the blood supply to one or both kidneys. Both possibilities may play a rôle in the production of the hypertension secondary to pyelonephritis.

The clinical significance of the observations reported here is clear. At the present time we have no explanation as to why some patients with pyelonephritis develop hypertension before renal insufficiency while some develop it only after the renal damage has become marked, and still others die in uremia with very little hypertension. This question merits and will receive further clinical and pathological study.

\section{PROTOCOLS}

Case 1: M. F. (Hospital Number 194,041), a girl of 9 years, came to the hospital September 1935 because of recurrent frontal headache and vomiting and urinary frequency. The family history was not contributory to the patient's illness. The past history showed her to have been a full term baby whose development was somewhat delayed. She had mumps and pertussis at 5 years of age and measles at 8 years. Ever since birth she had unusual frequency and nocturia. At 5 years of age she began to have severe headaches coming on every 2 to 3 months and lasting all day. At 7 years of age, vomiting began to accompany the headaches which became more frequent. During the past year she failed to gain and was fatigued very easily. Recently the headaches and vomiting occurred weekly. Four months before admission, she was found to have pus in her urine and was placed on a ketogenic diet without effect on the pyuria.

A physical examination revealed a thin, chronically ill, mentally alert girl. Both of the fundi showed albuminuric retinitis; there was edema of the optic discs, and the retinal arteries were narrowed, tortuous, and gave a light reflex. The heart was enlarged, a roentgenogram showing a cardiac diameter of $9.8 \mathrm{~cm}$. and an internal diameter of the chest of $18.5 \mathrm{~cm}$. The aortic arch was broad. There was a blowing systolic murmur and marked accentuation of the aortic second sound. The peripheral arteries were thickened but not beaded. The systolic blood pressure was 280 and the diastolic $170 \mathrm{~mm}$. Hg. The right kidney was palpable. The red blood cell count was $3,700,000$ per $\mathrm{cu} . \mathrm{mm}$. The hemoglobin was 72 per cent. The serum calcium was $9.6 \mathrm{mgm}$. per cent and the serum inorganic phosphorus $3.3 \mathrm{mgm}$. per cent. The blood urea nitrogen was $35 \mathrm{mgm}$. per cent and the serum protein 6.3 grams per cent. An intramuscular phenolsulphonephthalein test showed 27 per cent excretion in $300 \mathrm{cc}$. of urine in 3 hours. The urea clearance was 17 per cent of normal. The urine showed from a very slight trace to a large trace of albumin and numerous white blood cells per high power field.

Two weeks after admission she had a hypertensive crisis, the blood pressure rising to a systolic of 250 and a diastolic of $210 \mathrm{~mm}$. Hg. She became comatose, delirious, and had several convulsions. The urine became grossly bloody. A week later she appeared as she did at admission. Six weeks after admission the blood pressure rose to $260 \mathrm{~mm}$. $\mathrm{Hg}$ systolic and $230 \mathrm{~mm}$. $\mathrm{Hg}$ diastolic, and she had a generalized convulsion. Twelve days later a right splanchnic nerve resection was done, and after another 3 days the left splanchnic inerve was resected. Following the second operation she was very anemic and was given four transfusions. The anemia continued. Eight days later she became oliguric and developed a parotitis and pericardial friction rub and after two more days died in uremia with a blood nonprotein nitrogen of $187 \mathrm{mgm}$. per cent. Permission for an autopsy was not obtained.

Case 2: B. M. (Hospital Number 110,250), a girl of 8 years, entered the hospital in November 1931 because of recurrent attacks of headache, fever and vomiting throughout the previous 18 months. Frequent examination of the urine by the family doctor during this period had shown that it always contained pus.

The past history showed she had been a normal baby and had developed normally. She had had measles, pertussis, and chickenpox. Following tonsillitis at 3 years of age she had had a tonsillectomy and adenoidectomy. Immediately before the present illness she had had mumps.

The physical examination showed a well developed but small, undernourished, pale girl who appeared chronically ill. The significant positive findings follow. The retinal arteries showed increased light reflex, narrowing of the lumen and tortuosity. The disks were blurred and hyperemic. The heart sounds were loud and forceful. There was a soft systolic murmur with a marked accentuation of the aortic and pulmonic second sounds. Radial and brachial arteries were thickened. The systolic blood pressure was $210 \mathrm{~mm}$. $\mathrm{Hg}$ and the diastolic $170 \mathrm{~mm}$. Hg. On repeated examination the urine contained a very slight trace of albumin and 5 to 30 white blood cells per high power field in uncentrifuged specimens. On culture of the urine there was a growth of $B$. coli. The blood nonprotein nitrogen was $24 \mathrm{mgm}$. per cent. An intramuscular phenolsulphonephthalein test showed 50 per cent ex- 
cretion in two hours. A urea clearance was 65 per cent of normal. A urine concentration test showed an inability to concentrate above 1.012 .2

Two weeks after entry the headaches became more severe. The following day the patient had a hypertensive cerebral crisis. The blood pressure at this time was 240 $\mathrm{mm} . \mathrm{Hg}$ systolic and $170 \mathrm{~mm}$. $\mathrm{Hg}$ diastolic. The patient recovered from this cerebral accident, and the blood pressure in the course of the next week fell to $180 \mathrm{~mm}$. $\mathrm{Hg}$ systolic and $150 \mathrm{~mm}$. $\mathrm{Hg}$ diastolic. Before an examination of the urinary tract could be made the parents removed the child against our advice.

Case 3: R. E. (Hospital Number 107,386), a boy 7 years of age, entered the hospital in January 1933 with the chief complaint of severe headaches for several years and vomiting and convulsions during the past 9 months. He was a full term baby born following a normal labor. His early development was normal, except that he grew slowly, weighing 21 pounds at 2 years of age, 24 pounds at 3 years of age, and 32 pounds at 5 years of age. At 2 years of age he was found to have a marked phimosis which had caused pain on urination for the past 4 months. At this time there was some tenderness to pressure over the bladder, and the urine was found to contain a trace of albumin, but no white blood cells. A circumcision relieved the painful urination. He had pertussis at 2 years of age, had broken a wrist in a fall at 5 years of age, and one month before admission had received a blow over the left eye which had caused a hemorrhage into the eye which had been treated at the Boston City Hospital. He had had frequency and nocturia for several years. During the past 5 months the vomiting was frequently projectile. Two months before admission it was known that his systolic blood pressure was $220 \mathrm{~mm}$. $\mathrm{Hg}$.

Physical examination revealed a somewhat underdeveloped and undernourished boy weighing 37 pounds, who was mentally alert and in no apparent distress. The significant positive findings were as follows. Both retinas showed multiple scarring from old hemorrhages. The retinal arteries were narrow and the veins unusually tortuous. The disk margins were indistinct, and there was slight papilledema. The radial and brachial arteries were thickened. The heart was slightly enlarged to the left. The aortic second sound was greatly accentuated. The systolic blood pressure was $240 \mathrm{~mm}$. $\mathrm{Hg}$ and the diastolic blood pressure, $190 \mathrm{~mm}$. $\mathrm{Hg}$. The liver was $3 \mathrm{~cm}$. below the costal margin. The spleen was palpable. Repeated examination of the urine showed a slight trace of albumin but no sediment. The blood nonprotein nitrogen was $\mathbf{3 0}$ mgm. per cent. Serum calcium and phosphorus were normal. An intramuscular phenolsulphonephthalein test showed 32 per cent excretion in 2 hours. The urea clearance was 100 per cent of normal. A concentration test showed the specific gravity to be limited to 1.012 .2 Roentgenograms of the skull showed definite separation of the coronal and sagittal sutures indicating increased

2 We have noted such a discrepancy between the specific gravity and urea clearance tests in several of our patients with hypertension. intracranial pressure. Ventriculograms showed no localized distortion or filling defect. The very slight dilatation of the ventricles was consistent with a cerebral edema. The long bones were negative for lead. The red blood cells showed no stippling. The diagnosis of malignant hypertension of unknown etiology was made. The child was discharged to a convalescent home on February 28th with the same hypertension with which he entered. He died of cardiac failure August 9, 1933, without reentering the hospital. An autopsy performed outside the hospital ${ }^{8}$ showed the following : cardiac hypertrophy and dilatation, sclerosis of aorta, coronary and cerebral vessels, bilateral pyelonephritis and hydronephrosis, arteriolar nephrosclerosis, bilateral hydro-ureters, cystitis and dilatation of the bladder.

Case 4: R. W. (Hospital Number 143,483), an 11 year old boy, was admitted to the hospital October 14, 1930 , because of severe recurrent attacks of frontal headache, nausea, and vomiting beginning abruptly 11 months ago. The attacks occurred about once a week and were frequently precipitated by emotional disturbances. In addition to these symptoms there had been severe upper abdominal pain and dizziness over the past month. The family history was not relevant. The past history showed the patient to have been born a healthy child following a normal labor. His development was normal. He was reported to have had measles at 2 months of age, pertussis at 3 years, and repeated attacks of tonsillitis up to 2 years ago, when his tonsils and adenoids were removed.

Physical examination revealed a poorly developed slightly underweight child. The blood pressure was $260 \mathrm{~mm}$. $\mathrm{Hg}$ systolic and $180 \mathrm{~mm}$. $\mathrm{Hg}$ diastolic. The peripheral arteries were thickened. After rest, the blood pressure varied from 210 to 150 systolic and 160 to 120 diastolic. There was an albuminuric retinitis with hemorrhages and exudate. The heart was not enlarged. Following the administration of 0.12 gram of sodium nitrite by mouth the blood pressure fell from 200 systolic and 150 diastolic to 155 systolic and 130 diastolic, the hands became cold and fingers and face cyanotic, and the brachial, cubital and radial arteries became softer. The urine contained from a very faint trace to a trace of albumin, moderate and varying numbers of white blood cells, and occasional hyaline and granular casts. The urea clearance was 88 per cent of normal and the specific gravity of the urine varied from 1.020 to 1.005 .

One month after admission the pain in the left flank became severer, the temperature rose to $103^{\circ} \mathrm{F}$., the pyuria became more pronounced, and there was local tenderness and fullness in the left kidney region. The white blood count rose to 22,000 . It was at this time that the lower blood pressures were observed. An exploratory operation was deemed advisable. Through an incision running obliquely forward from the left side of the costovertebral angle the left kidney was exposed. The kidney was found to be markedly edematous. Toward

${ }^{3}$ We are indebted to Dr. Williams of the Rhode Island General Hospital for the autopsy report. 
the lower pole there was a large amount of cellulitis and a small amount of pus. Nothing was felt in the position of the adrenal. A drain was inserted to the infected area and the wound closed in layers to the drain. Pus drained from the wound for 10 days. The drain was then removed, and the wound healed well. The urine continued to show a few white blood cells. The albuminuric retinitis had now disappeared. After another 10 days the blood pressure began gradually to increase until it had again reached 220 systolic and 175 diastolic. At this time the spinal fluid pressure was $350 \mathrm{~mm} . \mathrm{H}_{2} \mathrm{O}$. Intravenous pyelograms showed the dye to be well concentrated and bilateral enlarged renal pelves and blunted calyces. The renal function remained unchanged.

On January 2, 1931, a second exploratory operation was performed through a left rectus incision from the costal margin to umbilicus and a transverse incision from umbilicus to perpendicular line from anterior superior spine. The right side of the abdomen, right kidney, and suprarenal was explored and nothing abnormal was made out. The peritoneum over the left kidney was incised and retracted. There was a moderate amount of inflammation about the enlarged left kidney. The left adrenal appeared normal.

Following the operation, the blood pressure continued its gradual rise reaching $250 \mathrm{~mm}$. $\mathrm{Hg}$ systolic and 180 $\mathrm{mm}$. $\mathrm{Hg}$ diastolic. At this time he had a hypertensive crisis with convulsions, pallor of left optic disc, and loss of sight. His heart showed slight left sided hypertrophy and a systolic murmur was heard at the apex. He recovered, regained his vision, and improved sufficiently to be discharged home to his family physician. The urine still showed a trace of albumin, rare white and red blood cells, epithelial cells and granular casts. The blood nonprotein nitrogen was not elevated, the red blood count was $4,900,000$ and hemoglobin 80 per cent. The blood pressure was $230 \mathrm{~mm}$. $\mathrm{Hg}$ systolic and $175 \mathrm{~mm}$. $\mathrm{Hg}$ diastolic.

He was readmitted to the hospital April 17, 1931, with cardiac failure. The blood pressure was $140 \mathrm{~mm}$. $\mathrm{Hg}$ systolic and $100 \mathrm{~mm}$. $\mathrm{Hg}$ diastolic. The urea clearance of 79 per cent was normal. He had repeated attacks of severe abdominal pain and dyspnea relieved by obstructing the venous return from the lower extremities. The cardiac decompensation increased, and he died 10 days after readmission.

Postmortem examination (A-31-68) showed bilateral chronic pyelonephritis and marked nephrosclerosis. Streptococcus hemolyticus was recovered from the heart's blood and from exudate in the right pleural cavity, the pericardial cavity, and the peritoneal cavity. Of particular importance in regard to the clinical story were the findings in the heart and vascular system, and in the kidneys. The heart was considerably enlarged, more marked on the left than the right side. On microscopic examination, diffuse fibrosis of the myocardium was found. There was generalized atheromatosis of the aorta. The smaller blood vessels of the pancreas, spleen, and periadrenal tissues were particularly involved. There was thickening of both the intima and the media with definite narrowing of the lumina of these vessels. Considerable perivascular fibrosis was also present.

The kidneys were not weighed but appeared definitely enlarged. They were firm in consistency and were enclosed in strongly adherent and thickened capsules to which the fibrosed periadrenal tissues were firmly attached. On section, the parenchyma was pale, yellowish brown in color and bulged into the line of incision. The cortex measured between 4 to $5 \mathrm{~mm}$. in thickness, and was poorly differentiated from the medulla. No striations or glomeruli could be recognized on the cut surface. The small arteries stood out conspicuously because of their thickened walls. The pelves of both kidneys were slightly dilated. No exudate was present. The ureters were of uniform caliber and showed no inflammatory changes grossly.

Five blocks were selected from the kidneys and sections were stained by several methods including Mallory's connective tissue stain. The main features were severe infection and vascular lesions. There was a widespread chronic and acute inflammatory process with considerable replacement fibrosis and occasional areas of acute inflammation which amounted to abscess formation. In a few fields, areas of parenchyma were completely necrotic and were replaced by masses of polymorphonuclear cells. The connective tissue stroma was edematous and was infiltrated with polymorphonuclear cells in scattered areas. The tubules showed acute degenerative changes. The epithelial lining cells were swollen, granular, and often contained fat or colloid droplets. Within the lumens of the tubules albuminous precipitate, hyaline and granular casts and cylinders composed of polymorphonuclear leukocytes were found. The arterioles were markedly thickened, and the lumens were decreased in many cases to the point of complete obliteration. Often, the walls of the arterioles were arranged in concentric rings in the characteristic onion layer arrangement. No hyaline deposits were found in the walls of the arterioles. The glomeruli showed various degrees of hyalinization of the vascular tufts up to complete hyaline change. Swelling of the endothelial cells with vacuolization was frequently noted in the capillaries of the glomeruli. In occasional areas where the acute inflammatory process in the renal parenchyma was most marked, the tufts of the glomeruli were infiltrated with polymorphonuclear leukocytes, and inflammatory cells and fibrin were occasionally noted in the capsular spaces. Large numbers of glomeruli, however, retained their normal appearance. (See Figure 1.)

The sequence of events cannot be stated with certainty. There is definite evidence of both old and recent pyelonephritis. It is impossible to state whether the arteriolar lesions in the kidney and in other organs of the body came before or after the initial infection of the kidneys. The association of vascular lesions of this type and pyelonephritis has been noted on several occasions in our laboratory. It should be emphasized, however, that the vascular lesions are not confined to the kidneys; the small vessels in the pancreas, spleen, and adrenals were also involved. The enlargement of the heart and the myocarditis are probably secondary to the vascular disease. 
Case 5: P. B. (Hospital Number 187,522), a boy of 7 years, entered the hospital in November 1934 because of hematuria 3 to 4 times a week for the past two months and occasional dysuria. The family history was noncontributory. He had had a normal infancy and always been well except for chickenpox at 4 months of age, mumps at 2 years and measles at 6 years. Physical examination showed a well developed and nourished boy with no abnormal findings. The blood pressure was $\mathbf{9 8}$ $\mathrm{mm}$. $\mathrm{Hg}$ systolic and $50 \mathrm{~mm}$. $\mathrm{Hg}$ diastolic. The urine contained a slight trace of albumin and was loaded with red blood cells. A roentgenogram of the abdomen showed a large solitary calculus at the lower pole of the right kidney. Intravenous pyelograms two days later showed the calculus in the region of the lower end of the right ureter. The right kidney pelvis was considerably dilated and the calyces were blunted. The right ureter was not outlined. The left kidney pelvis, calyces, and ureter were normal. The blood nonprotein nitrogen was $20 \mathrm{mgm}$. per cent. A phenolsulphonephthalein intramuscular test resulted in 30 per cent excretion in the first hour and 25 per cent excretion in the second hour. The following day Dr. W. E. Ladd exposed the lower end of the right ureter and removed the calculus. On analysis, 73 per cent of the dry material was ash composed of calcium oxalate, carbonate, and phosphate. Retrograde pyelography showed a markedly dilated right kidney pelvis with blunted calyces and a large tortuous right ureter. Culture of the urine from the left ureter and bladder gave no growth. The urine cleared, and the child was discharged to the outpatient department.

In January 1935, the urine contained many white blood cells and culture showed a growth of $B$. coli. In spite of hexamethylenamine, ammonium chloride and ketogenic diet therapy the pyuria and bacilluria continued. On April 5, a right nephrostomy was done by Dr. W. E. Ladd. At the lower pole of the kidney the fat was abnormally adherent, and there were several aberrant vessels, which did not, however, appear to compress the ureter. The pelvis of the kidney was greatly dilated and its wall thickened, and the ureter was markedly dilated and kinked on itself at the level of the lower pole of the kidney. An incision was made in the surface of the kidney pelvis, and catheter introduced down into the ureter. The kinking of the latter was partially relieved by freeing dense, fibrous tissue, and the catheter could then be passed without difficulty the whole length of the ureter. A silk purse string suture was then placed in the mid point of the convexity of the kidney, and by sharp and blunt dissection a hole was made through the cortex of the kidney into the pelvis. A large catheter was inserted through this and carried out through the original incision. The renal cortex was much thicker than anticipated.

On April 25, a phenolsulphonephthalein intramuscular test showed 15 per cent excretion from the nephrostomy drain in $32 \mathrm{cc}$. in the first hour and 10 per cent in $26 \mathrm{cc}$. the second hour. The catheter was removed April 30, the wound healed well, and the patient was discharged home May 13 with numerous white blood cells in the urine specimens.

On August 7 he still had pyuria. He was readmitted to the hospital on August 13 because of vomiting and rapid pulse for 5 days. The temperature was normal. $\mathrm{He}$ was cyanotic and dyspneic with respirations 48 and pulse 140 per minute. The liver was enlarged to the umbilicus and there was dependent edema. The heart was large, the diameter measuring $13.5 \mathrm{~cm}$. as compared to an internal diameter of the chest of $21.4 \mathrm{~cm}$. Auscultation of the heart showed dropped beats. The blood pressure was $130 \mathrm{~mm}$. $\mathrm{Hg}$ systolic and $100 \mathrm{~mm}$. $\mathrm{Hg}$ diastolic. There had never been any history suggesting rheumatic fever or any acute infection other than the pyelonephritis. After digitalization the pulse rate returned to normal, the dropped beats disappeared, there was a marked diuresis with loss of edema, and the blood pressure rose to $160 \mathrm{~mm}$. $\mathrm{Hg}$ systolic and $105 \mathrm{~mm}$. $\mathrm{Hg}$ diastolic. Urine from the right kidney contained $B$. coli and pus, and showed a 3 per cent excretion of intramuscularly injected phenolsulphonephthalein in one hour, while the left kidney gave 16 per cent excretion and no organisms on culture. A urine concentration test gave a specific gravity as high as 1.024 . The blood nonprotein nitrogen was $24 \mathrm{mgm}$. per cent. The sedimentation rate was normal. As there had been no hematuria or cylindruria characteristic of nephritis at any time during this admission and no drop in blood pressure with the diuresis, it was felt that an acute hemorrhagic nephritis on top of the pyelonephritis could not account for the elevated blood pressure. No source of infection other than the right pyelonephritis could be found. During the following seven weeks the blood pressure varied between 122 to 168 systolic and 90 to 110 diastolic. For the specific purpose of checking the hypertension and cardiac involvement, a right nephrectomy was done by Dr. W. E. Ladd on October 5. The ureter was found to be greatly dilated, tortuous, and to be covered with numerous firm fibrous adhesions. About two inches above the bladder, the ureter regained its normal appearance, so at this point it was clamped, ligated, and cut with cautery.

Examination of the right kidney and ureter showed the following. The gross specimen consisted of a right kidney measuring approximately $10 \times 6 \times 3 \mathrm{~cm}$., surrounded by a moderate amount of deep orange-colored perirenal fat. The capsule was thick, opaque, and in certain areas markedly adherent to the kidney surface. The external surface was a diffuse yellowish-brown in color, stippled with closely placed deep red punctate areas. Over the inferior pole was a large, irregular, slightly depressed dull purplish-red area to which the capsule was markedly adherent. At the superior pole were smaller discrete similar areas averaging $0.3 \mathrm{~cm}$. in diameter. The kidney was moderately firm but boggy and cut with ease revealing poorly defined cortical and medullary zones. The cortex was slightly swollen, measuring approximately $0.7 \mathrm{~cm}$. in thickness, slightly irregular, generally pale yellowish-brown in color with faint pinkish-gray linear 
radiations. At the superior pole there was a dull, moist, purplish-red, wedge-shaped lesion with a deep red central area, extending to the tip of an inferior calyx. The medulla was moist, pale brownish-yellow in color with faint red linear radiations. The pyramids were pale yellowish-brown, smooth and moist. The pelves and calyces were greatly dilated with moist, rough granular mucosal surfaces, dirty bluish-yellow in color flecked with numerous small bright and dark red pin-point lesions. The ureter was dilated, measuring $2.8 \mathrm{~cm}$. in circumference. It was redundant and kinked but patent. The mucosa was swollen, thickened, wrinkled, and dirty yellowishgray in color. Numerous small irregular bright red pinpoint lesions were scattered over the mucosal surface. The specimen was sectioned and fixed in Zenker's solution and 10 per cent Formalin solution.

Six sections of kidney and two sections of ureter were stained by various methods including Mallory's connective tissue stain. There was some thickening, edema, and lymphocytic infiltration of the capsule. The interstitial tissues were densely infiltrated by lymphocytes, polymorphonuclear leukocytes, and mononuclear cells. In occasional areas the renal parenchyma was replaced by polymorphonuclear leukocytes and lymphocytes. In other areas, lymphocytes were packed so densely that a suggestion of lymph follicle formation was noted. Inflammatory changes extended throughout the entire kidney and were prominent in the subpelvic tissues. The convoluted and collecting tubules were dilated, and the lining epithelium showed cloudy swelling, fragmentation of the cytoplasm, and in some areas flattening of the epithelium. Occasional tubules were filled with polymorphonuclear leukocytes. In many of the glomeruli there was increased prominence of the basement membrane both in the capillary loops and in the capsule itself. Many glomeruli were practically bloodless. The basement membrane was particularly thickened in the areas of greatest inflammatory infiltration, and the capsules of the glomeruli showed fibrosis and hyalinization. In a number of instances there were adhesions between the glomerular tufts and the capsule. Inflammatory cells in the glomeruli were lacking. Moderate thickening of both the media and intima of the smaller arterioles was noted. Edema, acute and chronic inflammation, and congestion were noted beneath the mucosa of the ureters. (See Figure 2.)

Postoperatively the blood pressure fell to $100 \mathrm{~mm}$. $\mathrm{Hg}$ systolic and $70 \mathrm{~mm}$. $\mathrm{Hg}$ diastolic, and the urine was clear. During the subsequent 20 months, examination at six outpatient visits have shown that the heart has been of normal size, the urine negative for pus and bacteria, the blood pressure never higher than $115 \mathrm{~mm}$. $\mathrm{Hg}$ systolic and $75 \mathrm{~mm}$. $\mathrm{Hg}$ diastolic, and the urea clearance within normal limits.

Case 6: Dr. J. D. Barney's patient. A girl 10 years of age with a history of pyuria of at least two years' duration was admitted to the hospital March 1937 with a bacilluria and a varying number of white blood cells in the urine and a hypertension of $190 \mathrm{~mm}$. $\mathrm{Hg}$ systolic and $120 \mathrm{~mm}$. $\mathrm{Hg}$ diastolic pressure. The blood nonprotein nitrogen and the excretion of phenolsulphonephthalein were within normal limits. The day following the removal of the right kidney by Dr. Barney the blood pressure fell to $110 \mathrm{~mm}$. $\mathrm{Hg}$ systolic and 70 diastolic and remained below that level during the subsequent stay in the hospital. Three months later, when the child was last seen, she appeared to be a healthy active child, and the blood pressure was 92 systolic and 60 diastolic. Dr. T. B. Mallory described the kidney as a small irregularly scarred kidney with dilated pelvis and slightly injected ureter, which on section showed a most marked thickening of the media and intima of the arterioles and an infiltration of cells in areas throughout the parenchyma and beneath the epithelium of the pelvis and several calyces.

I wish to acknowledge my indebtedness to Dr. Sidney Farber for the pathological descriptions of Cases 4 and 5 and for his coöperation in reviewing with me many cases of pyelonephritis, and to thank Dr. J. D. Barney and Dr. T. B. Mallory for permitting reference to their case.

\section{BIBLIOGRAPHY}

1. Ritter, S. A., and Baehr, G., The arterial supply of the congenital polycystic kidney and its relation to the clinical picture. J. Urol., 1929, 21, 583.

2. Bell, E. T., and Pedersen, A. H., The causes of hypertension. Ann. Int. Med., 1930, 4, 227.

3. Volhard, F., Die Doppelseitigen Hämatogenen Nierenerkrankungen. Julius Springer, Berlin, 1918.

4. Schwarz, H., Kidney diseases in infants and children. II. Malignant hypertension nephritis : primary sclerotic kidney (Schrumpfniere). Am. J. Dis. Child., 1924, 27, 233.

5. Longcope, W. T., and Winkenwerder, W. L., Clinical features of the contracted kidney due to pyelonephritis. Bull. Johns Hopkins Hosp., 1933, 53, 255.

6. Weiss, S., Parker, F., Jr., and Robb, G. P., A correlation of the hemodynamics, function, and histologic structure of the kidney in malignant arterial hypertension with malignant nephrosclerosis. Ann. Int. Med., 1933, 6, 1599.

7. Fishberg, A. M., Hypertension and Nephritis. Lea and Febiger, Philadelphia, 1934, 3d ed.

8. Peters, J. P., Some factors in the etiology of Bright's disease. New England J. Med., 1935, 213, 653.

9. Peters, J. P., Lavietes, P. H., and Zimmerman, H. M., Pyelitis in toxemias of pregnancy. Am. J. Obst. and Gynec., 1936, 32, 911.

10. Zimmerman, H. M., and Peters, J. P., Pathology of pregnancy toxemias. J. Clin. Invest., 1937, 16, 397.

11. Kimmelstiel, P., and Wilson, C., Inflammatory lesions in the glomeruli in pyelonephritis in relation to hypertension and renal insufficiency. Am. J. Path., 1936, $12,99$. 
12. Butler, A. M., and Lanman, T., Examination of the child with chronic pyelonephritis. New England J. Med. (In press).

13. Amberg, S., Hypertension in the young. Am. J. Dis. Child., 1929, 37, 335.

14. Moritz, A. R., Personal communication.

15. Parker, F., Jr., and Weiss, S., The nature and significance of the structural changes in the lungs in mitral stenosis. Am. J. Path., 1936, 12, 573.
16. Goldblatt, H., Lynch, J., Hanzal, R. F., and Summerville, W. W., Studies on experimental hypertension. I. The production of persistent elevation of systolic blood pressure by means of renal ischemia. J. Exper. Med., 1934, 59, 347.

17. Wood, J. E., Jr., and Cash, J. R., Experimental hypertension-observations on sustained elevation of systolic and diastolic blood pressure in dogs. J. Clin. Invest., 1936, 15, 543. 